\title{
Psicoterapia de grupo: noções básicas
}

Group psychotherapy: basic notions

Luis Paulo C.Bechelli e Manoel Antônio dos Santos, Editora Legis Summa,
Ribeirão Preto, 2001

Rodrigo SANChes Peres ${ }^{1}$
Por ser decorrente de uma necessidade relacionada à atividade didática dos autores, o livro Psicoterapia de grupo: noções básicas prima pela objetividade. Ressalte-se, contudo, que o texto não peca, em momento algum, pela superficialidade. Desse modo, pode-se mostrar proveitoso tanto para os interessados em estabelecer um contato inicial com o tema quanto para os iniciados que buscam uma referência capaz de subsidiar a ampliação de seus conhecimentos.

No primeiro capítulo, o psiquiatra Luiz Paulo C. Bechelli e o psicólogo Manoel Antônio dos Santos, autores da obra, apresentam um breve, porém valioso, histórico da psicoterapia de grupo. Para isso, sintetizaram as contribuições dos principais precursores dessa modalidade assistencial, demonstrando como, ao longo do século XX, seu método e sua finalidade evoluíram, respectivamente, da aula para a interação e da reeducação para a mudança terapêutica.

Já o segundo capítulo tem como intuito a sistematização dos fundamentos para o desenvolvimento de um programa de psicoterapia de grupo. A duração do tratamento, a frequiência das sessões, o número de participantes e outros temas de caráter prático são então levantados. Paralelamente, uma discussão sobre as diversas estratégias e técnicas de psicoterapia de grupo existentes torna patente que todos os modelos teórico-metodológicos já descritos são relativamente equivalentes em termos dos resultados produzidos na maioria das condições clínicas.

Os procedimentos empregados na psicoterapia de grupo em consultório particular são abordados no terceiro capítulo. Trata-se de um relato de experiência profícuo, pois a maioria das obras especializadas focaliza essencialmente as aplicações dessa modalidade assistencial em instituições. Nesse sentido, é possível afirmar que o terceiro capítulo se afigura como uma rara referência para o profissional que pretende trabalhar com grupos em sua própria clínica.

O desenvolvimento de um programa de psicoterapia de grupo é o assunto do quarto capítulo. Os autores partem de considerações gerais acerca das vicissitudes inerentes aos diferentes estágios do trabalho grupal para chegar a diretrizes específicas para a conduta do psicoterapeuta. Assim, salientam a importância da criação de uma abertura para o diálogo, o que exige do psicoterapeuta o domínio de uma ampla gama de recursos técnicos e, dos pacientes, a motivação para buscar soluções para suas dificuldades.

1 Psicólogo pela Universidade Estadual Paulista (Unesp), mestre e doutorando em Psicologia pela Universidade de São Paulo (USP), docente da Universidade Federal de São Carlos (UFSCar).

Endereço para correspondência: Rua Jesuíno de Arruda, 2.753 - 13560-060 - São Carlos, SP. Fone: (16) 3371-7054. E-mail: rodrigosanchesperes@yahoo.com.br 
O quinto capítulo, por sua vez, oferece ao leitor uma funcional categorização dos principais fatores terapêuticos grupais. Esclarecem-se, então, os meios pelos quais determinados fenômenos decorrentes das ações tanto do psicoterapeuta quanto dos pacientes funcionam como mediadores dos processos de mudança. O estudo dos fatores terapêuticos, a propósito, destaca-se como um tema promissor de pesquisa em psicoterapia de grupo. Por essa razão, esse capítulo pode servir como um importante ponto de partida para o desenvolvimento de trabalhos científicos relacionados ao assunto.

Apoiando-se em uma consistente revisão da literatura, os autores fornecem no sexto capítulo um panorama dos benefícios esperados em cada um dos estágios do trabalho grupal. Os principais indicadores prognósticos também são traçados, o que evidencia que a participação ativa do paciente no tratamento é indispensável. Ademais, a importância da aliança terapêutica - fenômeno cujo surgimento e manutenção dependem da habilidade e da sensibilidade do psicoterapeuta na arte da composição do grupo - é colocada em relevo.

O sétimo e último capítulo aborda resumidamente a evolução da psicoterapia de grupo e o surgimento de novas técnicas para o exercício dessa prática, ambos movimentos motivados, por um lado, pelas necessidades que se produzem a partir dos impasses inerentes ao trabalho clínico e, por outro, pelas inovações introduzidas com o avanço dos aportes teóricos que lhe servem de base. Por fim, é preciso salientar que o livro apresenta uma ampla bibliografia, oferecendo, conseqüentemente, diversas indicações para futuros estudos.

\section{Eventos}

Esta seção da revista está aberta para divulgar eventos nacionais e internacionais.

0 material poderá ser enviado à Assistente Editorial Sandra Lúcia B. Picchiotti.

Instituto de Psiquiatria, Rua Ovídio Pires de Campos, 785 - 05403-010 - São Paulo - SP ou por e-mail: revpsiq@usp.br

Encontros sobre História da Medicina

Data: 3 e 19 de outubro e 7, 9 e 23 de novembro de 2006

Local: Anfiteatro do $4^{\circ}$ andar do Instituto de Psiquiatria da FMUSP,

São Paulo-SP

Horário: das $12 \mathrm{~h}$ às $13 \mathrm{~h} 30$

E-mail: lupaula@usp.br

XXIV Congresso Brasileiro de Psiquiatria

Data: 25 a 28 de outubro de 2006

Local: Curitiba-PR

Informações: Associação Brasileira de Psiquiatria

Fone/Fax: (21) 2199-7500/2221-4409

E-mail: congresso@abpbrasil.org.br

Home page: www.abpbrasil.org.br

XIV World Congress of the International Society of Psychiatric

Genetics: (ISPG)

Data: 28 de outubro a $1^{0}$ de novembro de 2006

Local: Cagliari, Itália

Home-page: www.wcpg2006.it

XXIV Congresso de la Asociación Latinoamericana de Psiquiatria

(APAL)

Data: 1 - a 4 de novembro de 2006

Local: Santo Domingo, República Dominicana

Informações: www.apal2006.com/articlefiles/apal2006_pre_programa.pps

Simpósio Comemorativo dos 10 anos da ASTOC

Avanços no diagnóstico e tratamento do transtorno obsessivo-

compulsivo e da síndrome de Tourette

Data: 24 e 25 de novembro de 2006

Local: Anfiteatro do Instituto de Psiquiatria da FMUSP, São Paulo-SP

Informações: ASTOC

Fone: (11) 3284-1678

E-mail: astoc@terra.com.br
V Semana de Psiquiatria - 0 novo IPq: conquistas e desafios

Data: 28 a 30 de novembro de 2006

Local: Anfiteatro Paulo Vaz de Arruda do Instituto de Psiquiatria da FMUSP Informações: www.psiquiatria.incubadora.fapesp.br/portal/programa5se manadepsiquiatria089.doc

E-mail: lucia.grande@hcnet.usp.br

\section{WPA Regional Conference}

Data: 30 de novembro a 3 de dezembro de 2006

Local: Lima, Peru

Informações: www.wpanet.org/bulletin/wpaeb4003.html

E-mail: app@appperu.org

$1^{\text {st }}$ European Congress of INA \& $2^{\text {nd }}$ Mediterranean Congress

Data: 7 a 10 de dezembro de 2006

Local: Atenas, Grécia

E-mail: secretaria@ina-wfsbp-dualcongress.gr

Home page: www.ina-wfsbp-dualcongress.gr

$2^{\text {nd }}$ International Congress of Biological Psychiatry

Data: 17 a 21 de abril de 2007

Local: Santiago, Chile

Home page: www.wfsbp-santiago2007.com

$1^{\text {st }}$ European Congress of International Neuropsychiatric Association (INA) $2^{\text {nd }}$ Mediterranean Congress

Data: 7 a 10 de dezembro de 2006

Local: Atenas, Grécia

Informações: www.ina-wfsbp-dualcongress.gr

E-mail: secretaria@ina-wfsbp-dualcongress.gr

$2^{\text {nd }}$ Internacional Congress of Biological Psychiatry

Data: 17 a 21 de abril de 2007

Local: Santiago, Chile

Informações: www.wfsbp-santiago2007.com 